\title{
A Case of Direct Thermal Esophageal Injury Caused by Hot Noodle-Soup
}

\author{
Faiza Ahmed*, David Mendez and Syed Siddiqi
}

Department of Gastroenterology, USA

ISSN: 2637-7632

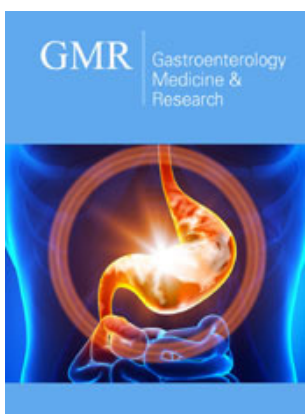

*Corresponding author: Faiza Ahmed, Department of Gastroenterology, USA

Submission: 啙 March 02, 2020

Published: : March 09, 2020

Volume 4 - Issue 4

How to cite this article: Faiza Ahmed, David Mendez, Syed Siddiqi. A Case of Direct Thermal Esophageal Injury Caused by Hot Noodle-Soup. Gastro Med Res. 4(4). GMR.000591. 2020.

DOI: 10.31031/GMR.2020.04.000591

Copyright@ Faiza Ahmed, This article is distributed under the terms of the Creative Commons Attribution 4.0 International License, which permits unrestricted use and redistribution provided that the original author and source are credited.

\section{Introduction}

Esophageal thermal injury can develop due to the ingestion of hot food and liquids [1], left atrial catheter ablation [2], caustic ingestion, or by smoking freebase cocaine [3]. Since direct thermal injury is not a known cause of esophageal ulcer, these rare cases can be easily overlooked by physicians [4]. We herein introduce the case of a woman whom we suspected to experience thermal injury-induced esophageal ulcers (Table 1).

Table 1: Causes of esophageal ulcers leading to cancer.

\begin{tabular}{|l|l|}
\hline & Left atrial catheter ablation \\
\hline & High Temperature Foods \\
\hline & High Temperature Liquids \\
\hline & Left atrial catheter ablation \\
\hline & Freebase cocaine \\
i. & Caustic Ingestion \\
ii. & Causes injury to esophagus and stomach. \\
iii. & Alkali ingestion: usually damages the esophagus more than stomach or duodenum. \\
\end{tabular}

In the emergency room, we came across a case of a 27 year-old-female who presented with a two-day history of odynophagia, dysphagia, burning sensation at the throat and severe upper chest pain that commenced immediately after she consumed spicy hot pot noodle soup for lunch in haste. The patient reported that she had ingested these noodles in the past without any problems and enjoys spice in her food. She eats spicy food regularly with no complications. This was the first time she felt these symptoms following the consumption of her meal. On arrival, the vital signs were normal and laboratory tests were unremarkable. Her clinical examination was also normal. She denied any epigastric pain and acid regurgitation. There was no history of gastroesophageal reflux, or usage of drugs or any corrosive substances. She also informed us of not receiving any previous medical procedures. She underwent upper gastrointestinal endoscopy which revealed esophageal thermal injury. Her endoscopic findings displayed two linear ulcers that measured $0.6 \mathrm{~cm} \times 0.3 \mathrm{~cm}$ each. In the middle third of the esophagus, there was one linear ulcer that measured $1.1 \mathrm{~cm} \mathrm{x} 0.2 \mathrm{~cm}$. The patient was prescribed $40 \mathrm{mg}$ of pantoprazole (once a day) and $10 \mathrm{mg}$ of tiapride (three times a day). During her two-week follow-up appointment, an endoscopy was repeated, which demonstrated a complete healing of the ulcers.

Foods are usually consumed by humans in two stages-mastication, followed by deglutition [5]. The chewing step is important because it helps with the loss of heat in the consumed food, which reduces the direct thermal exposure to the esophageal mucosa [6]. This is contrary to the way food was consumed in this patient's case. Hot pot noodles and soup do not require much chewing and can be easily swallowed. The heat was still present in the noodles as it made contact with the esophagus, thereby leading to ulceration. Also, since the food bolus is 
known to slow down in the middle third of the esophagus (at the level of aorta) [6], the patient experienced chest pain. This was also one of the sites of injury.

The literature is rife with case studies and reports of esophageal injuries that were caused by exposure to chemicals [7-9]. Esophageal ulcers are also known to be directly linked with aphthous stomatitis, malignancy and infections [10]. But in this unique case, we clearly see that ingestion of hot foods without chewing can lead to esophageal ulcers. Soups should be also handled carefully and not be ingested while they are at high temperatures. Large cross-sectional studies are required to further explore this association and establish causality.

\section{References}

1. Dutta SK, Chung KY, Bhagavan BS (1998) Thermal injury of the esophagus. N Engl J Med 339(7): 480-481.

2. Halm U, Gaspar T, Zachäus M, Sack S, Arya A, et al. (2010) Thermal esophageal lesions after radiofrequency catheter ablation of left atrial arrhythmias. Am J Gastroenterol 105(3): 551-556.

3. Cohen ME, Kegel JG (2002) Candy cocaine esophagus. Chest 121(5): 1701-1703.

4. Lim CH, Yen HH, Su W, Lim CJ, Sai TH, et al. (2017) Extensive causative esophagitis caused by thermal injury: A case report and review of the literature. Case Reports in Gastrointestinal Medicine 2017: 8243567.

5. Matsuo K, Palmer JB (2008) Anatomy and physiology of feeding and swallowing: Normal and abnormal. Physical Medicine and Rehabilitation Clinics of North America 19(4): 691-697.

6. Matsuo K, Palmer JB (2009) Coordination of mastication, swallowing and breathing. The Japanese Dental Science Review 45(1): 31-40.

7. Baehr PH, Donald MC (1998) GB: Esophageal disorders caused by infection, systemic illness, medications, radiation and trauma. ( $6^{\text {th }}$ edn), In: Feldman M, Scharschmidt BF, Sleisenger MH (Eds,). Sleisenger and Fordtran's Gastrointestinal and Liver Disease. pp. 519-539.s

8. Shahbazzadegan B, Samadzadeh M, Feizi I, Shafaiee Y (2016) Management of esophageal burns caused by caustic ingestion: A case report. Iranian Red Crescent Medical Journal 18(11): e12805.

9. Thomas MO, Ogunleye EO, Somefun $O$ (2009) Chemical injuries of the oesophagus: Aetiopathological issues in Nigeria. J Cardiothorac Surg 4: 56.

10. Higuchi D, Sugawa C, Shah SH, Tokioka S, Lucas CE (2003) Etiology, treatment, and outcome of esophageal ulcers: A 10-year experience in an urban emergency hospital. J Gastrointest Surg 7(7): 836-842. 